\title{
PELATIHAN APLIKASI HOME VISIT SEBAGAI PENYEDIA JASA TERAPI KEPADA ANAK DISABILITAS INTELEKTUAL(DI)
}

\author{
Novrini Hasti ${ }^{1}$, Febilita Wulan Sari ${ }^{2}$,Tine Agustin Wulandari ${ }^{3}$, dan Andri Sahata Sitanggang ${ }^{4}$ \\ ${ }^{1}$ Sistem Informasi(Universitas Komputer Indonesia) \\ ${ }^{2}$ Ilmu Hukum (Universitas Komputer Indonesia) \\ ${ }^{3}$ Ilmu Komunikasi(Universitas Komputer Indonesia) \\ ${ }^{4}$ Sistem Informasi(Universitas Komputer Indonesia) \\ E-mail: andri.sahata@email.unikom.ac.id
}

\begin{abstract}
ABSTRAK. Banyak keluhan orang tua yang mengalami keterbatasan dalam melakukan perawatan merawat anak Disabilitas Intelektual(DI), yang mana disabilitas intelektual memerlukan penanganan secara khusus. Keterbatasan orang tua tersebut dikarenakan mereka harus berkerja ataupun keterbatasan pengetahuan dalam melakukan terapi. Pelatihan ini ditujukan kepada orang tua yang memiliki anak Disabilitas Intelektual melalui sebuah Aplikasi Home Visit khususnya di Kota Cimahi. Pelatihan tersebut adalah melakukan pendampingan untuk melakukan pendaftaran pelayanan jasa terapis melalui aplikasi, tanpa harus datang ke lokasi terapi. Metode yang diterapkan dalam kegiatan ini adalah dengan menggunakan metode dialog, diskusi bersama, serta pendampingan dalam penggunaan aplikasi. Dikarenakan pandemi Covid 19, kegiatan dibagi menjadi 2 bagian, 1. Secara offline untuk kegiatan dialog dan diskusi bersama tim CTC(Cimahi Terapi Center) seperti terapis, administrasi, serta pemilik CTC, sedangkan untuk kegiatan kedua dilakukan secara online yaitu pelatihan pendampingan aplikasi Home Visit kepada para orang tua. Pembuatan Aplikasi Jasa Terapi ini merupakan kegiatan yang berhasil menginsiasi para orang tua yang memiliki anak Disabilitas Intelektural untuk menggunakan jasa terapis secara online serta membantu pihak CTC dalam menangani permasalahan orang tua yang memiliki anak Disabilitas Intelektual.
\end{abstract}

Kata kunci: Aplikasi; Jasa Terapis; Disabilitas Intelektual; CTC; Pelatihan

ABSTRACT. Many parents complain that they have limitations in taking care of children with Intellectual Disabilities (DI), in which intellectual disabilities require special treatment. The limitations of these parents are because they have to work or have limited knowledge in doing therapy. This training is aimed at parents who have children with Intellectual Disabilities through a Home Visit Application, especially in Cimahi City. The training is to provide assistance to register therapist services through the application, without having to come to the therapy location. The method applied in this activity is to use the method of dialogue, joint discussion, and assistance in using the application. Due to the Covid 19 pandemic, the activity is divided into 2 parts, 1. Offline for dialogue and discussion activities with the CTC (Cimahi Therapy Center) team such as therapists, administration, and CTC owners, while the second activity is carried out online, namely training for assisting the Home Visit application. to parents. Making this Therapy Service Application is an activity that has succeeded in initiating parents who have children with intellectual disabilities to use online therapist services and assisting the CTC in dealing with the problems of parents who have children with intellectual disabilities.

\section{Keywords: Applications; Therapist Services; Intellectual Disabilities; CTC}

\section{PENDAHULUAN}

Mengacu pada Undang-Undang Republik Indonesia Nomor 8 Tahun 2016 tentang Penyandang Disabilitas bahwa adanya kesamaan kesempatan dalam memberikan peluang dan/atau menyediakan akses kepada penyandang Disabilitas untuk menyalurkan potensi dalam segala aspek penyelenggaraan negara dan masyarakat, maka penyandang disabilitas memi-liki hak yang sama sebagai warga negara Indonesia. Dalam undang-undang ini pun diatur bahwa diberikan perlindungan dan aksesibilitas yang sama di mata masyarakat dalam kemudahan yang disediakan untuk Penyandang Disabilitas guna mewujudkan kesamaan kesempatan. Oleh karena itu maka penyandang disabilitas berhak mendapatkan semua pelayanan publik yang berlaku di Indonesia.

Pelayanan tersebut adalah kegiatan atau rangkaian kegiatan dalam rangka pemenuhan kebutuhan pelayanan sesuai dengan ketentuan peraturan perundang-undangan bagi setiap warga negara dan penduduk atas barang, jasa, dan/atau pelayanan administratif yang disediakan oleh penyelenggara pelayanan publik. Adapun pasal 2 dalam Pelaksanaan dan Pemenuhan hak Penyandang Disabilitas berasaskan:1. Penghormatan terhadap martabat, 2. otonomi individu, 3. tanpa Diskriminasi, 4. partisipasi penuh, 5. Keragaman manusia dan kemanusiaan, 6.KesamaanKesempatan, 7.Kesetaraan, 8. Aksesibilitas, 9. Kapasitas yang terus berkembang dan identitas anak, 10. Inklusif serta perlakuan khusus dan Pelindungan lebih. Dengan alasan tersebut seharusnya ada pelayanan juga yang diberikan kepada kaum disabilitas yang sama dengan pelayanan kepada masyarakat, khususnya pemamfaatan teknologi yang diberikan dalam meningkatkan pelayanan kepada DI.

Hingga saat ini, layanan yang diberikan kepada anak DI hanya diberikan oleh orang tua 
saja tanpa pengetahuan secara khusus, mereka hanya mengandalkan informasi yang diperoleh dari media atau pun orang lain secara langsung. Hal ini mengakibatkan kurangnya perkembangan pada anak DI tersebut. Permasahan itu dapat terjadi karena orang tua harus bekerja atau terbatasnya waktu yang mereka miliki sehingga perawatan yang dilakukan tidak secara intensif dilakukan. maka dibutuhkan peran orang ketiga dalam melakukan mediasi penyembuhan secara berkala. Salah satu solusi dapat ditempuh oleh orang tua adalah menggunakan jasa terapis dari suatu Lembaga/Ahli Terapis yang dapat menangani Disabilitas Intelektural. Akan tetapi pada kenyataanya, para orang tua mengalami kesulitan untuk mendapatkan jasa terapis disabilitas intelektual dikarenakan keterbatasan informasi, hanya beberapa tempat yang dapat menyediakan kebutuhan jasa terapis ini

Oleh karena itu keterlibatan perguruan tinggi diharapkan menjadi jembatan bagi para orang tua dan lembaga penyedia Jasa Terapi yakni CTC, untuk dapat dipertemukan melalui Aplikasi Home Visit. Aplikasi ini bertujuan aplikasi yang memudahkan masyarakat/ para orang tua untuk mendapatkan layanan dari Ahli terapi penyandang disabilitas dari CTC

\section{METODE}

Motode yang dilakukan ada 2 langkah, yaitu metode pendekatan kepada orang tua. Dan metode pendekatan kepada teknologi.

1. Metode Pendekatan kepada orang tua

Berawal dari permasalahan mengenai keterbatasan informasi mengenai jasa terapis Disabilitas Intelektua(DI), maka tim pengabdian melakukan kegiatan non teknis seperti :

a. Dialog, tim pengabdian masyarakat melakukan pertemuan dengan para anak yang memiliki DI (Disabilitas Intelektual), dialog tersebut mengajukan beberapa pertanyaan, kesulitan apa yang dihadapi oleh orang tua, pengetahuan apa yang dimiliki orang tua dalam merawat anak (DI), serta layanan apa saja yang sudah pernah didapatkan dari lembaga yang menangani secara khusus untuk anak DI.

b. Kemudian tim pengabdian melakukan diskusi bersama dengan para orang tua yang memiliki anak DI, dan saling bekerja sama untuk mendapatkan solusi, maka diperoleh hasil diskusi tersebut mengenai jenis dukungan teknologi seperti apa yang mempermudah orang tua mendapatkan jasa layanan terapis.

c. Sedangkan untuk mempersiapkan aplikasi home visit, maka tim pengabdian melakukan kunjungan kepada para orang tua, untuk mengetahu sampe sejauh mana mereka menggunakan teknologi atau aplikasi pada smartphone mereka, hal ini bertujuan agar para tim pengabdian dapat melihat gambaran secara umum aplikasi yang digunakan, sehingga menjadi contoh bagi tim dalam membuat aplikasi dengan pola aplikasi yang serting digunakan oleh para orang tua. Hal ini untuk memudahkan para orang tua memudahkan dalam penggunaan aplikasi.

\section{Metode Pendekatan Aplikasi}

Sedangkan metode kedua yaitu melakukan penerapan TTG tersebut kepada masyarakat/mitra serta melakukan evaluasi kegiatan dari aplikasi yang diterapkan. Kegiatan ini menggunakan beberapa pendekatan, antara lain:

Adapun pendekatan yang dilakukan dalam menerapkan metode analisis rancangan aplikasi sebagai berikut.

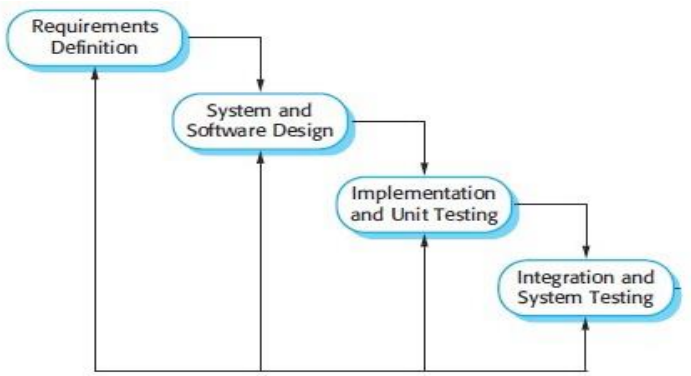

Gambar 1. Pendekatan Kebutuhan Data

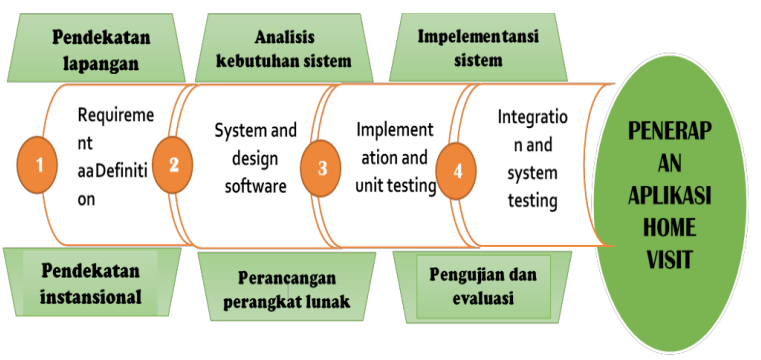

Gambar 2. Pendekatan Aplikasi

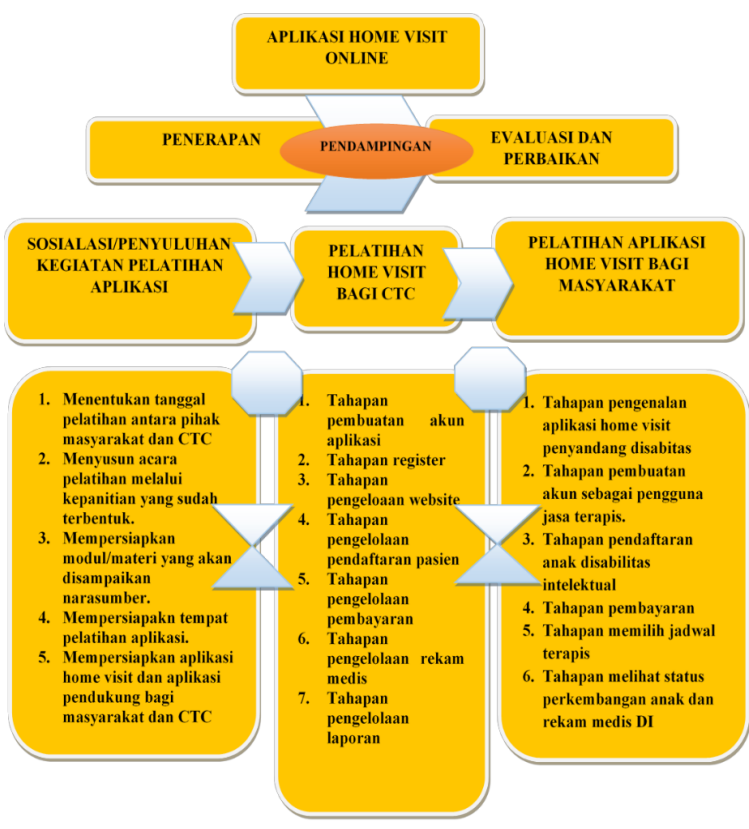

Gambar 3. Penerapan Aplikasi 


\section{HASIL DAN PEMBAHASAN}

Kegiatan ini dilaksanakan dengan kolaborasi antara Tim CDC, jasa terapis dan para orang tua yang memiliki anak disabitlias, yang telah dilaksanakan pada bulan Mei-Juni 2021 dengan tim pelaksana pengabdian yang menjadi pemateri yang dilaksanakan di Universitas Komputer Indonesia berjalan lancar dan sukses sesuai target dan luaran yang ingin dicapai dari kegiatan pengabdian kepada masyarakat ini.

Adapun kegiatan ini dilakukan melalui beberapa tahapan baik secara online dan offline yaitu:

1. Dialog dan diskusi bersama para jasa terapi CDCdilakukan secara langsung dengan offline atau tatap muka. Dialog dan diskusi ini membahas bagaimana cara dalam menangani anak disabilitas Intelektual(DI). Dialog dan diskusi tersebut dapat terlihat pada gambar 4 .
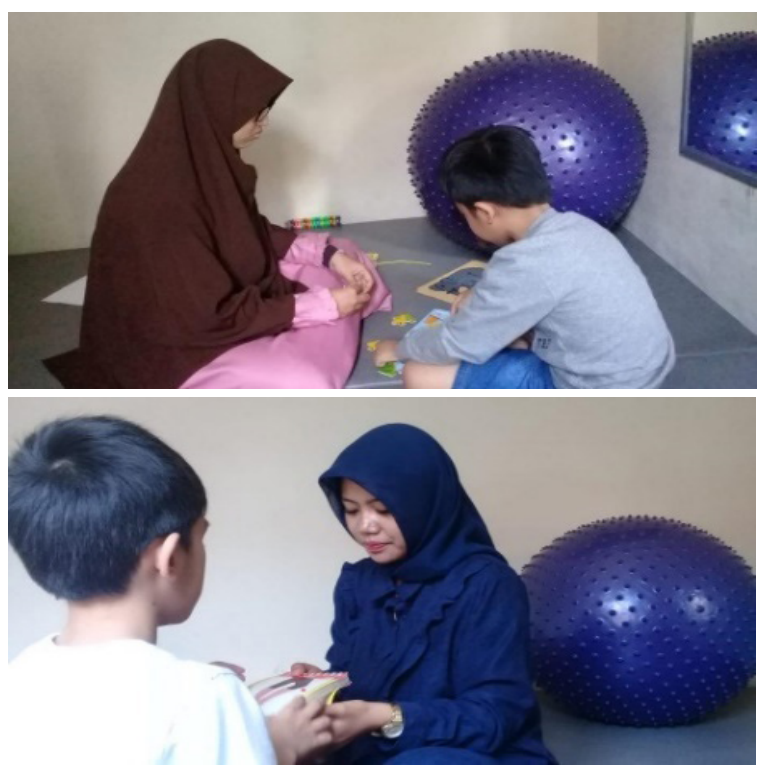

Gambar 4. Dialog dan Diskusi Dengan Jasa Terapi

Kegiatan ini dilakukan dengan tujuan para jasa terapi sudah memiliki kualifikasi yang baik dalam menangani anak disabilitas intelektual, para tim pengabdian mengikuti kegiatan yang dilakukan oleh jasa terapi di CDC dari awal hingga selesainya kegiatan terapi tersebut. Dalam kegiatan ini juga dilakukan diskusi apa yang menjadi kesulitan orang tua dalam merawat anak terapi, dan hasil diskusi tersebut memang dibutuhkan suatu keahlian dan kesabaran serta ketegasan dalam mendidik anak disabilitas, dan ilmu tersebut yang jarang dimiliki oleh para orang tua dan hanya para jasa terapi yang sudah memilki sertifikat khusus dalam menangani anak disabilitas tersebut.

Berdasarkan dialog yang dilakukan dengan orang tua yang memiliki anak disabilitas, bahwa harus adanya kemudahan dalam mendapatkan jasa layanan terapi dari lembaga yang bersertfikat, dalam hal ini yayasan CDC, maka hasil diskusi antara pemilik CDC, jasa terapi dan para orang tua dihasilkanlah untuk dibuatnya aplikasi yang dapat diakses oleh para orang tua untuk mendaftarkan anaknya pada aplikasi Home Visit, sehingga para jasa terapi yang ada di CDC dapat dijadwalkan, dan dapat langsung ke tempat para orang tua yang memilki anak disabilitas tersebut.

2. Dialog bersama tim mahasiswa pembuat aplikasi Berdasarkan hasil diskusi yang dilakukan oleh para orang tua, Pemilik CDC, dan jasa terapi, maka tim pengabdian mengajak mahasiswa untuk berdiskusi dalam pembuatan aplikasi. Pelibatan mahasiswa ditujukan untuk mereka dapat juga belajar bagaiamana menerapkan aplikasi pada masyarakat berdasarkan permasalahan yang terjadi, atau praktek pada saat mereka dapat mengembangkan aplikasi pada masyarakat. Adapun dokumentasi tersebut dapat dilihat pada gambar 5 .

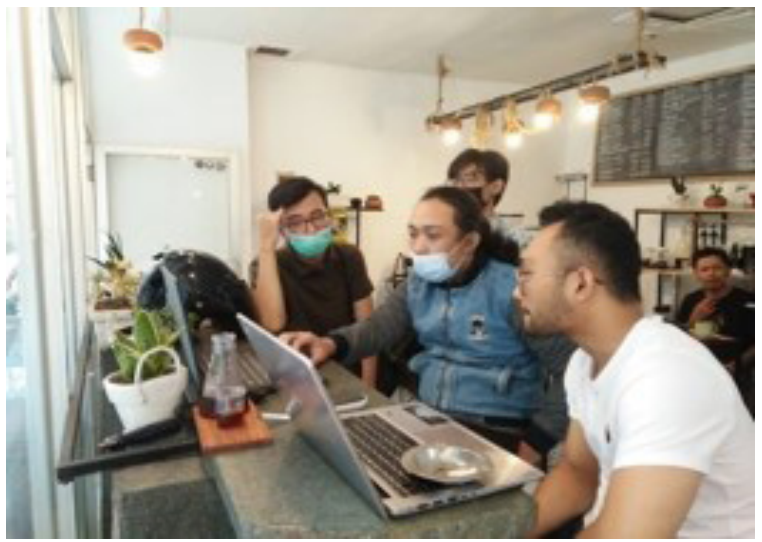

Gambar 5. Dialog Bersama Mahasiswa

Hasil diskusi diperoleh pembahasan mengenai perancangan aplikasi berbasis web, meliputi perancangan :

a) Antar muka/interface/Company Profile dari CDC.

Perancangan ini harus dibuat sesederhana mungkin, seperti aplikasi umumnya yang sering digunakan oleh masyarakat, agar mudah diakses oleh orang tua dan jasa terapis. Perancangan ini dimaksudkan agar masyarakat dapat mengetahui Lembaga CDC sebagai penyedia jasa terapi yang bersertifikat dan terpercaya

b) Perancangan Home Visit.

Bagaimana penjadwalan jasa terapis dan dapat diinformasikan kepada para orang tua sehingga mereka dapat memilih jadwal yang sesuai dengan waktu para orang tua.

c) Perancangan Teknologi GPS

Perancangan ini bertujuan agar para jasa terapi dapat menemukan titik lokasi tempat tinggal para orang tua pada saat menggunakan jasa layanan terapi online.

d) Perancangan Medical Record.

Ditujukan untuk para orang tua dapat melihat perkembangan anak yang sudah menggunakan 
jasa layanan terapi dari CDC. Medical record ini berbentuk laporan setiap bulannya.

3. Pendampingan Teknologi/aplikasi bersama para orang tua, jasa terapi dan pemilik CDC.

Adapun kegiatan ini adalah mendampingi para peserta yang terlibat agar memilki pengetahuan dalam menggunakan aplikasi, sehingga pada saat implementasi dapat dijalankan sesuai dari diskusi yang sudah dilakukan. Kegiatan ini dilakukan secara daring. Berikut pertemuan yang dilakukan dapat dilihat pada gambar 6 .

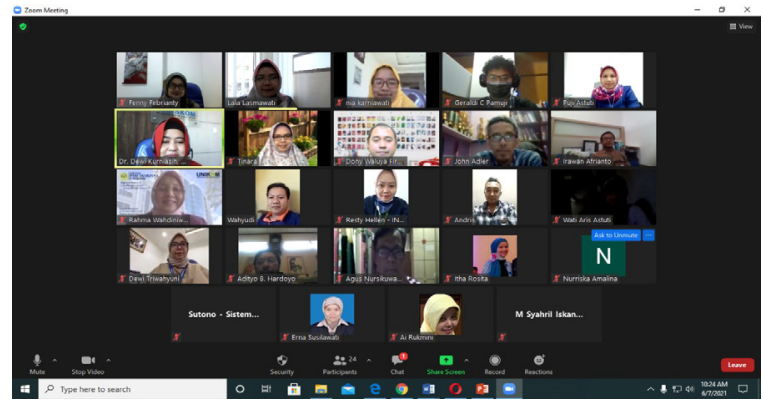

Gambar 6. Para peserta PKM

Adapun kegiatan ini meliputi dari kegiatan pembukaan acara, oleh ketua tim pengbdian, Ketua CDC dan perwalilan para orang tua. Setelah itu dilanjutkan dengan pemaparan penggunaan aplikasi yang dilakukan oleh anggota tim pengabdian.

Maka kegiatan selanjutnya dapat dilihat dari beberapa dokumentasi yang dilakukan mengenai materi yang disampaikan.

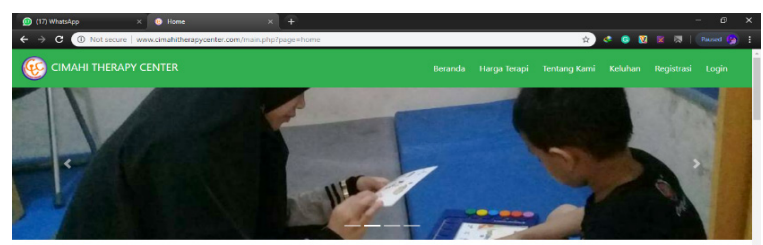

Downsyndrome

Gambar 7. Tampilan Website CDC

Halaman awal ketika para orang tua membuka halaman website dengan alamat url www. cimahitherapycenter.com. Halaman ini menyediakan segalajenis informasimengenai lokasi CTC, layanan apa saja yang diberikan CTC, cara pemesanan jasa terapis, pembayaran.

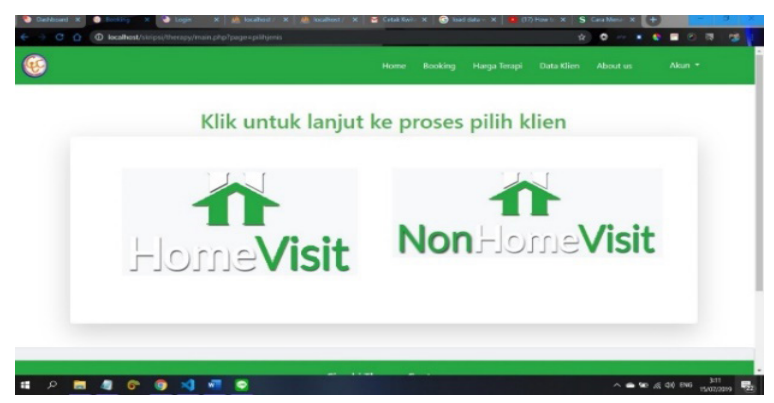

Gambar 8. Layanan Home Visit Atau Non Home Visit
Pada bagian ini pemateri menjelaskan proses untuk dalammennetukanjenis layanan yang diberikan CDC. Jika Home Visit maka jasa terapi akan datang langsung kerumah orang tua tersebut tetapi jika non home visit maka para orang tua memilih jadwal untuk datang langsung ketempat CDC tersebut. Kedua layanan ini juga harus menentukan waktu/ jadwal yang tersedia dari pihak CDC.

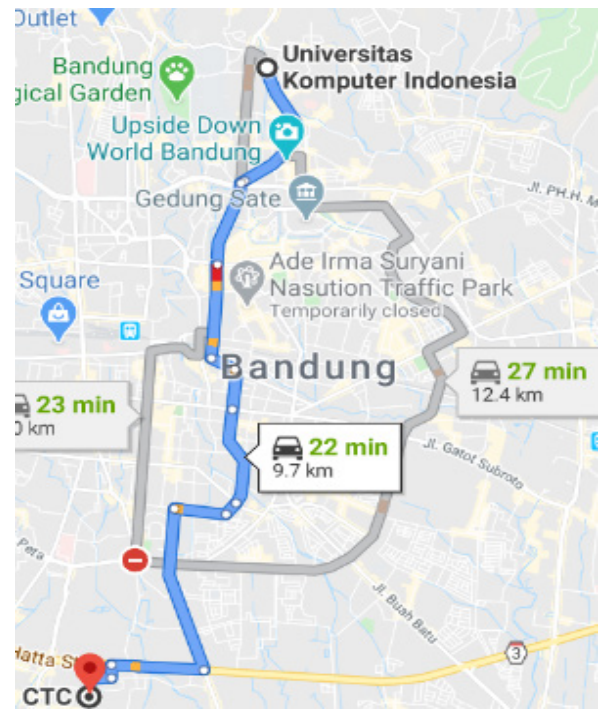

Pada bagian ini pemateri menjelaskan bahwa GPS digunakan untuk para orang tua dan jasa terapi bisa saling mengetahui posisi keberadaan masingmasing dalam penggunaan Home Visit, hal ini juga membantu para jasa terapi dalam pencarian lokasi para orang tua

\section{SIMPULAN}

Dengan adanya kegiatan yang dilakukan secara online merupakan salah satu penerapan keantusiasan para orang tua dalam penggunaan teknologi khususnya menggunakan aplikasi virtual jarak jauh, dilanjutkan dengan pendampingan penggunaan aplikasi secara virtul, para orang tua semangat dalam memberikan pertanyaan-pertanyaan bagaimana menggunakan semua fitur-fitur tersebut sehingga para orang tua bisa menggunakan aplikasi dengan tahapan bagaimana membuka website, melakukan pendaftaran anak disabilitas, kemudian pemilihan fasilitas Home Visit serta Non Home Visit, Pemilihan Jadwal, serta melihat laporan medical record. Kegiatan ini dilengkapi dengan workshop, jadi setiap masing-masing orang tua didampingi oleh para mahasiswa dalam penggunaan aplikasi. Maka kegiatan sudah berhasil ditandai dengan para peserta dapat menjawab pertanyaan-pertanyaan tahapan penggunaan aplikasi Home Visit dengan baik.

\section{UCAPAN TERIMAKASIH}

Ucapan terimakasih kepada Direktorat Sumber Daya, Direktorat Jenderal Pendidikan Tinggi, Kementrian 
Pendidikan Kebudayaan Riset dan Teknologi dengan nomor kontrak 087/E4.1/AK.04.PT/2021 yang telah mendanai kegiatan pengabdian ini hingga selesai, dan kepada pihak CTC telah bersedia untuk menjadi objek dalam penerapan teknologi melalui Aplikasi Home Visit.

\section{DAFTAR PUSTAKA}

Nursikuwagus, A., Sari, F. W., \& Sitanggang, A. S. (2019). Pkm Pendekatan Teknologi Melalui Aplikasi Cerdas Penolong Masyarakat Untuk Meningkatkan Kepercayaan Masyarakat Terhadap Kepolisian Atas Tindak Pidana/ Kejahatan Di Kecamatan Coblong Bandung. Dharmakarya, 8(2), 74.
R. Sitanggang, A. S., Wahyuni, W., Syafariani, R. F., \& Arianto, A. (2019). Penerapan Aplikasi Scout Learning Berbasis Multimedia Dalam Meningkatkan Pengembangan Inovasi Minat Dan Bakat Ekstrakurikuler Bagi Sekolah Dasar Negeri 127 Sekeloa Bandung. Jurnal Pengabdian Kepada Masyarakat, 9(1), 21.

Imelda, Rohmawati, T., Sujana, A. P., \& Sitanggang, A. S. (2019). Pkm Penerapan Teknologi Mobile Dalam Jasa Travel Berbasis Smart City. 04(01), 364-371.

R. Fenny Syafariani Dan Andri Sahata. (2017). Penyuluhan Pemasaran Dan Pelatihan Inovasi Panganan Hortikultura Desa Nagrog Cicalengka (Jawa Barat). Journal Of Empowerment, 1(2), 121-138. 